\title{
Atlantoaxial Subluxation Secondary to Unstable Os Odontoideum in a Patient With Arrested Hydrocephalus Due to Congenital Aqueductal Stenosis: A Case Report
}

\author{
ABOLFAZL RAHIMIZADEH, MD,${ }^{1}$ WALTER L. WILLIAMSON, $\mathrm{MD},{ }^{2}$ SHAGHAYEGH RAHIMIZADEH, \\ MD, ${ }^{2}$ MAHAN AMIRZADEH, $\mathrm{MS}^{1}$ \\ ${ }^{I}$ Department of Spinal Surgery, Pars Advanced and Minimally Invasive Medical Manners Research Center, Pars Hospital, Tehran, Iran, ${ }^{2}$ Adventist Hinsdale Hospital, \\ Hinsdale, Illinois
}

\begin{abstract}
Background: In a small percentage of children born with congenital hydrocephalus, enlargement of the head and the presence of ventriculomegaly may halt and ultimately stabilize the condition designated as arrested hydrocephalus. Arrested hydrocephalus in children is typically due to congenital aqueduct stenosis, which can be described appropriately as a stasis existing within the channel between the third and fourth ventricles. Os odontoideum (OO) is an uncommonly occurring pathology at the craniovertebral junction. Although the clinical and radiologic features of its existence and the therapeutic options for its pathology have been widely discussed within the medical literature, its true etiology has been a source of divisive debate, proposing both a traumatic as well as a congenital mechanism. The etiology of $\mathrm{OO}$ has been heartily debated in the literature for several years as well. Most authors have come to support a posttraumatic causality. However, strong evidence exists to support a congenital origin to this rarely observed malformation.

Methods: Within this case study we present a 24-year-old woman with atlantoaxial subluxation that exists secondary to an orthotropic OO. The patient had a history of arrested hydrocephalus due to congenital aqueductal stenosis beginning in early childhood. She presented with normal intelligence and was neurologically without deficits before the occurrence of an atlantoaxial dislocation. Unfortunately, the pathology was initially misdiagnosed as a decompensation state of the arrested hydrocephalus, and after 8 months the patient became wheelchair bound. Following this unfortunate event the correct diagnosis was ultimately uncovered. Subsequently a C2-1 instrumentation procedure resulted in excellent alignment and fusion.
\end{abstract}

Conclusions: To the best of our knowledge, this is the first example of an aqueduct stenosis in the setting of an existing $\mathrm{OO}$, a combination that might be another clue in favor of a congenital etiology.

Cervical Spine

Keywords: aqueduct stenosis, arrested hydrocephalus, etiology, os odontoideum

\section{INTRODUCTION}

Os odontoideum (OO), or separate odontoid, is a well-known pathology that was described for the first time in the 19th century. Os odontoideum has a Latin origin composed of os (bone) and odontoideum (toothlike). ${ }^{1-8}$ An OO might remain asymptomatic for several years until a minor trauma triggers its instability. Once a stable atlantoaxial dislocation becomes destabilized, gait disturbances with quadriparesis will often result. The paresis is usually more prominent in the lower extremities. Urinary urgency will also occur in conjunction with the stark motor losses. These phenomena are due to the presence of a cervicomedullary compression as the result of atlantoaxial subluxation. ${ }^{1-8}$
In hydrocephalic children the reestablishment of cerebrospinal fluid (CSF) dynamics in terms of flow and pulsatility may allow the patient to become clinically stable despite the presence of ventriculomegaly and macrocephaly. ${ }^{9-12}$ When both occur simultaneously it is designated as an arrested hydrocephalus (AH). ${ }^{9-12}$ A patient with $\mathrm{AH}$ might remain asymptomatic until a trauma of low intensity destabilizes and decompensates a hydrocephalic state. ${ }^{13}$ Gradual increases in cerebrospinal pressure in such patients will result in gait disturbances, with spastic paraparesis and urinary urgency. ${ }^{14}$

The etiology of $\mathrm{OO}$ has been debated in the literature. ${ }^{14,15}$ Whereas most authors support a 


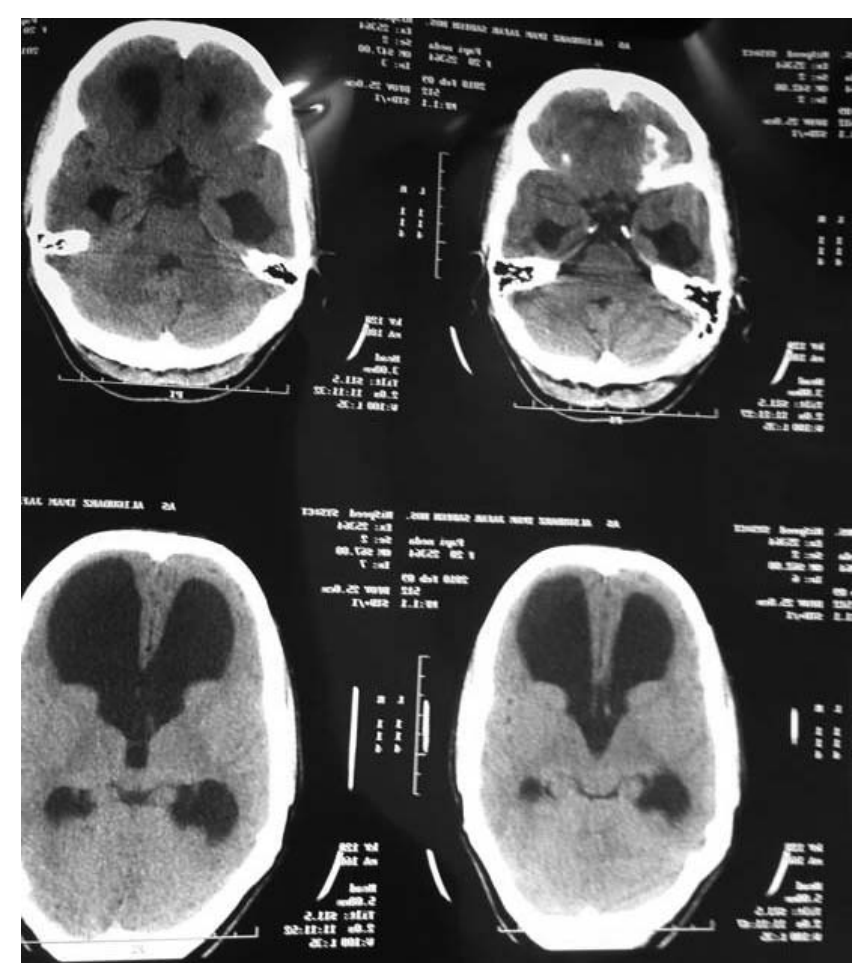

Figure 1. Brain computed tomography scan showing enlarged lateral and third ventricles, whereas the fourth ventricle is very small, indicating aqueduct stenosis.

posttraumatic etiology, some evidence exists to support a congenital origin. ${ }^{1-8}$

The theory proposing a congenital origin is presumed to involve a failure in the fusion of the ossification centers of the dens as well as the corresponding ossification centers of the body of the axis. ${ }^{16-18}$ This condition can be considered as a part of the spectrum of odontoid dysplasia, including odontoid agenesis and ossiculum terminalis. ${ }^{15-17}$

In traumatic theory, once the broken dens is separated from the axis body it likely loses its vascular supply and gradually remodels to become an OO. ${ }^{1-8,15,16,19}$

Herein, in a case study several aspects of the presence of $\mathrm{OO}$ in a young woman with arrested hydrocephalus are explored.

Furthermore, similarities between destabilized arrested hydrocephalus and $\mathrm{OO}$ that may cause some confusion in a medicolegal setting or even lead to inappropriate treatments will be discussed.

\section{CASE REPORT}

A 24-year-old female patient was initially admitted because of progressive weakness of the extremities with a debilitating difficulty in ambulating during an

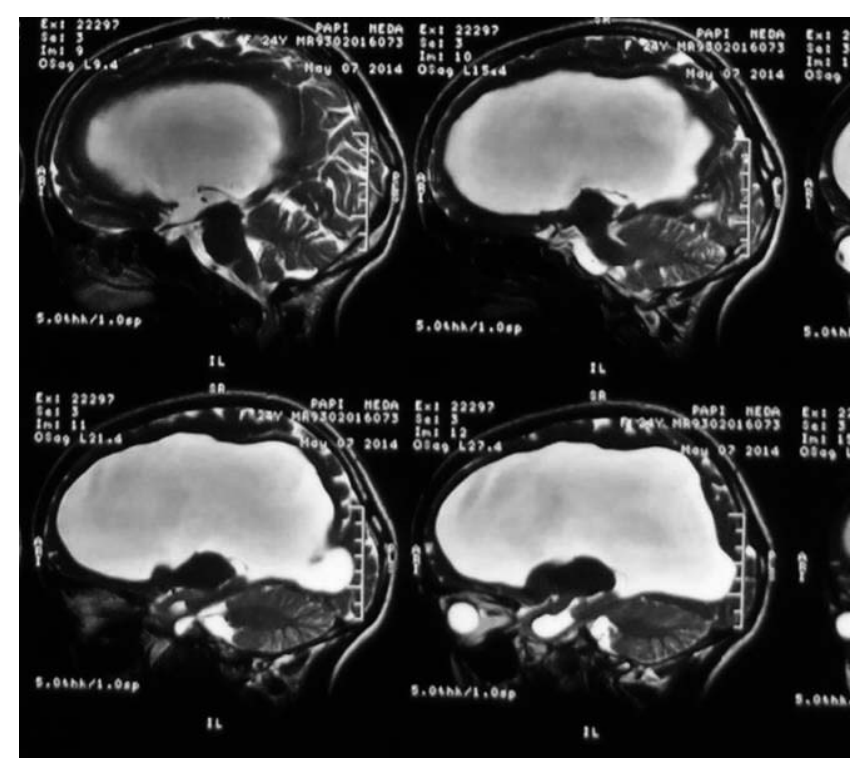

Figure 2. Brain magnetic resonance imaging demonstrating enlarged lateral ventricles without any edema around the ventricles, which points to arrested hydrocephalus, and small fourth ventricle compatible with aqueduct stenosis.

8-month period. The wheelchair-bound woman had a history of arrested hydrocephalus due to aqueductal stenosis from early childhood. Up until a few months before admission she was quite active and was of normal intelligence. This is evidenced by the fact that she possessed an MS in psychology. Nine months earlier she experienced a single trivial fall while running to catch a bus. Then, at 7 months before admission, she noted to her physician that she could no longer walk properly. Her inability to step normally was then wrongly attributed to the destabilization and decompensation of the arrested hydrocephalus by local neurosurgeons who were debating about the most appropriate treatment to consider given her current condition (Figures 1 and 2). A delay in her diagnosis took about 5 more months, during which time she became unable to walk entirely and was nearly bedridden. Fortunately, the correct diagnosis of cervicomedullary compression was arrived at and she was then referred to our institute for further care and evaluation. Upon admission she was found to be a well-educated woman with a relatively large head who was unable to stand or walk. The circumference of her head was measured to be $69 \mathrm{~cm}$. Neurologic examination revealed marked spastic quadriparesis, which was more prominent in the lower extremities and manifested with hyperactive reflexes and upturned toes.

Magnetic resonance imaging (MRI) was the first diagnostic tool used, and it demonstrated a severe narrowing at the cervicomedullary region caused by 


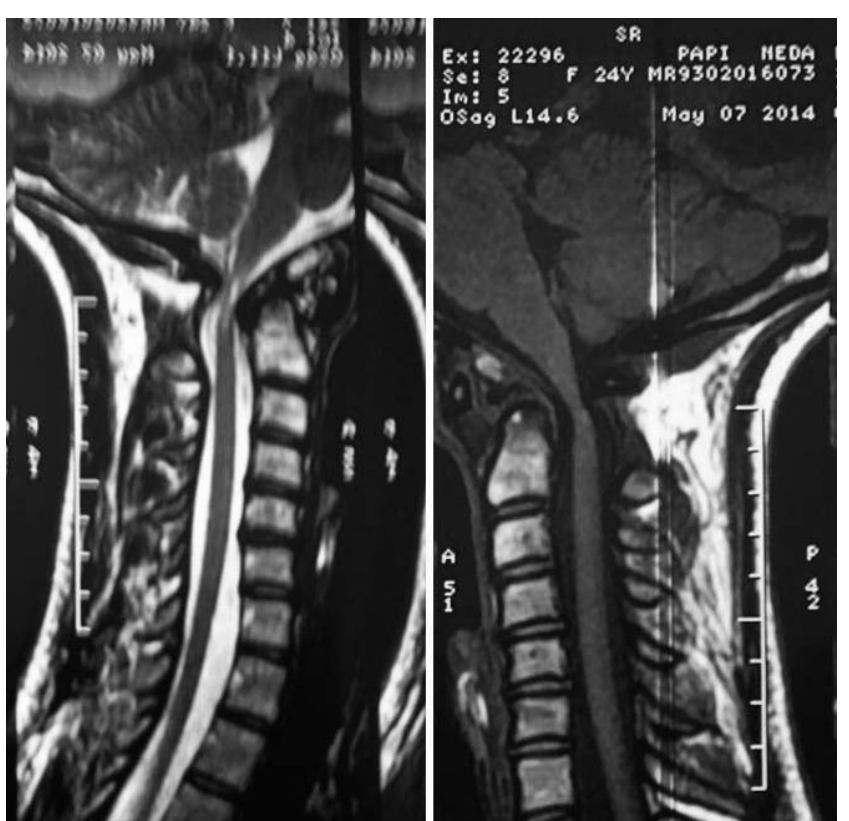

Figure 3. T1-weighted sagittal magnetic resonance imaging (MRI) showing marked narrowing at craniovertebral junction; in T2-weighted sagittal MRI, myelopathy at this region is demonstrated.

a forward atlantoaxial dislocation which was presumed to be due to OO (Figure 3). An X-ray and later reformatted sagittal and coronal computed tomography (CT) scans confirmed the presence of an $\mathrm{OO}$ with a reducible atlantoaxial dislocation (Figures 4 and 5). The discovery of a "jigsaw" pattern, which is evidence for the congenital etiology of $\mathrm{OO}$ development, was observed clearly within the sagittal CT scan.

Using the imaging obtained through the variety of aforementioned diagnostic tools, C1-2 screw rod fixation for an unstable, reducible, atlantoaxial subluxation as a sequel of free-floating $\mathrm{OO}$ was ultimately decided upon. Under general anesthesia and with the patient in the prone position, the stabilization of $\mathrm{C} 1$ and $\mathrm{C} 2$ with the proper alignment was accomplished successfully. $\mathrm{C} 2$ pedicle screws were used bilaterally. The atlas required that one side use a lateral mass screw, and on the contralateral side a laminar hook was employed (Figure 6).

The postoperative course was uneventful, and she was discharged on the fourth postoperative day in a Minerva orthosis. At a 2-month follow-up appointment, weakness and spasticity of the extremities had notably decreased, and she was able to stand with the help of 2 persons. Postoperative MRI at this time showed appropriate decompression, although the myelopathic patch was present (Figure 7). At a 6-month follow-up encounter she was able to walk

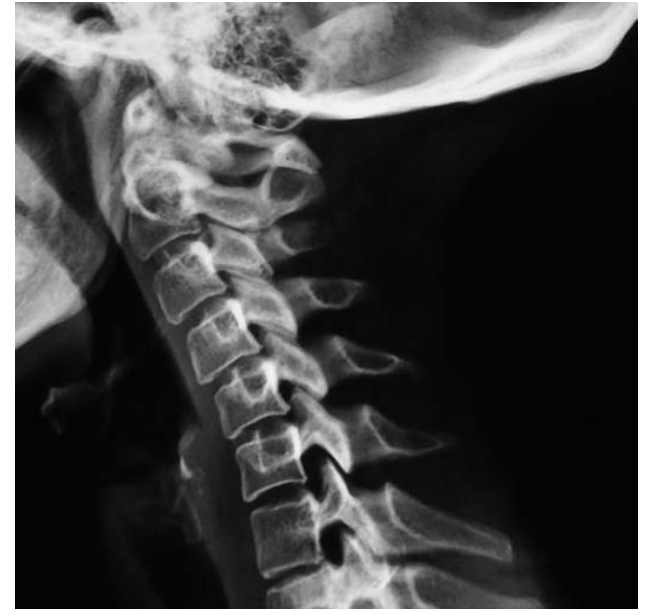

Figure 4. Lateral cervical radiograph, showing displaced atlas arch and os odontoideum posteriorly.

with the aid of only a walker. The Minerva Collar was discontinued at this time. One year after surgery she was able to ambulate independently but with some difficulty. Now, 18 months following surgical intervention, no further improvement in her walking has been observed. Lateral cervical X-ray at this time demonstrated a suitable alignment and excellent bony fusion (Figure 8).

\section{DISCUSSION}

Hydrocephalus is an active distension of the ventricular system of the brain resulting from the inadequate passage of CSF from its point of production within the cerebral ventricles to its point of absorption within the systemic circulation.

Stenosis of the aqueduct of Sylvius is a congenital anomaly that prevents the free flow of CSF toward the fourth ventricle, resulting in hydrocephalus. Hydrocephalus due to this anomaly presents in early childhood with an enlargement of the head and the sunset deviation of the eyes. Hesitation in treatment results in massive macrocephaly that will not decrease through the use of therapeutic means and will hence require a surgical intervention. Surgical approaches to hydrocephalus due to aqueductal stenosis have been traditionally through the use of ventriculoperitoneal shunts. Most recently endoscopic third-ventricle ventriculostomy has become the first-line surgical intervention.

Infrequently, hydrocephalus due to aqueductal stenosis in its course may reach equilibrium between the production of CSF and its absorption by the ependymal layer of the lateral and third ventricles. $^{9-12}$ As a result, the head enlargement 

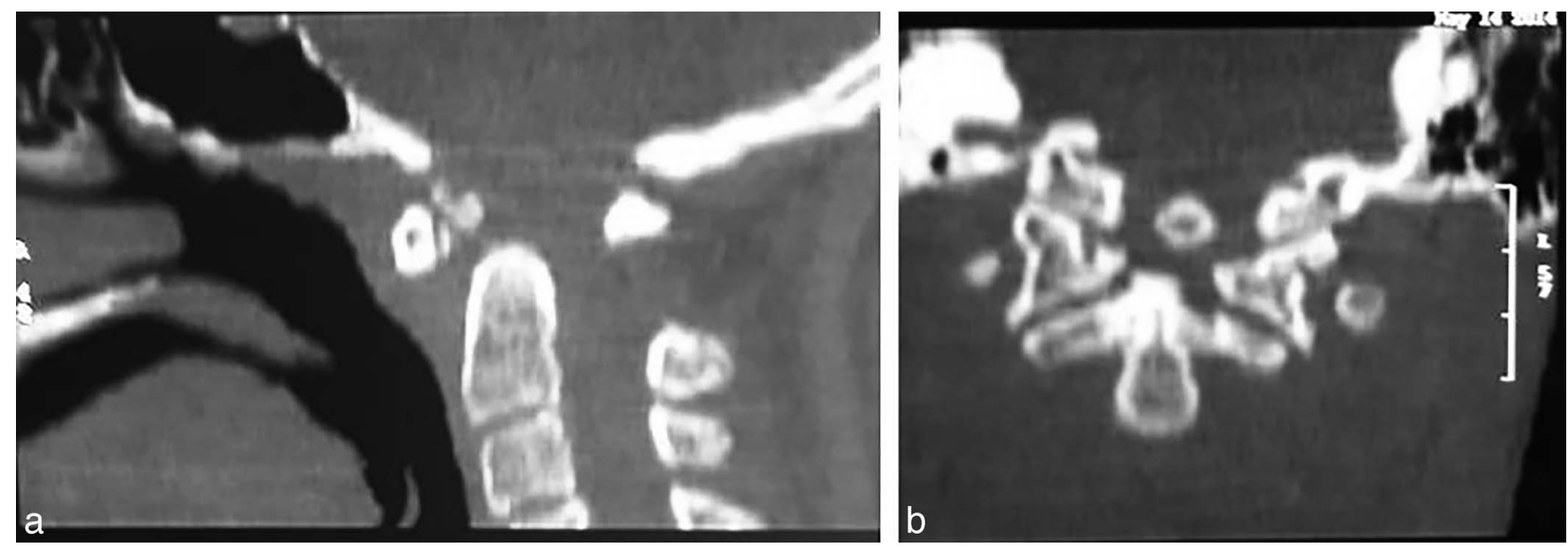

Figure 5. (a) Sagittal and (b) coronal reconstructed computed tomography demonstrating an os odontoideum.

ceases to increase, a condition that is aptly designated as arrested hydrocephalus. ${ }^{9-12}$

$\mathrm{OO}$, on the other hand, is an anomaly of the cervical spine in which the normal odontoid process is replaced by an ossicle possessing smooth circumferential cortical margins that have no osseous continuity with the body of the axis. ${ }^{1-8}$

\section{Etiology}

Since its initial description, the etiology of OO has been a matter of debate, and two principal theorems-both the acquired and the congenital-have been proposed to explain its occurrence. $^{1-8,14,15}$

\section{Acquired Posttraumatic}

Bachs et $\mathrm{al}^{19}$ were the first to propose neck and head trauma in childhood as the cause of OO. In their paper from 1955, they described a 49-year-old man with progressive quadriparesis due to a separate odontoid. ${ }^{19}$ Accordingly, because the patient had been kicked by a horse when he was 2
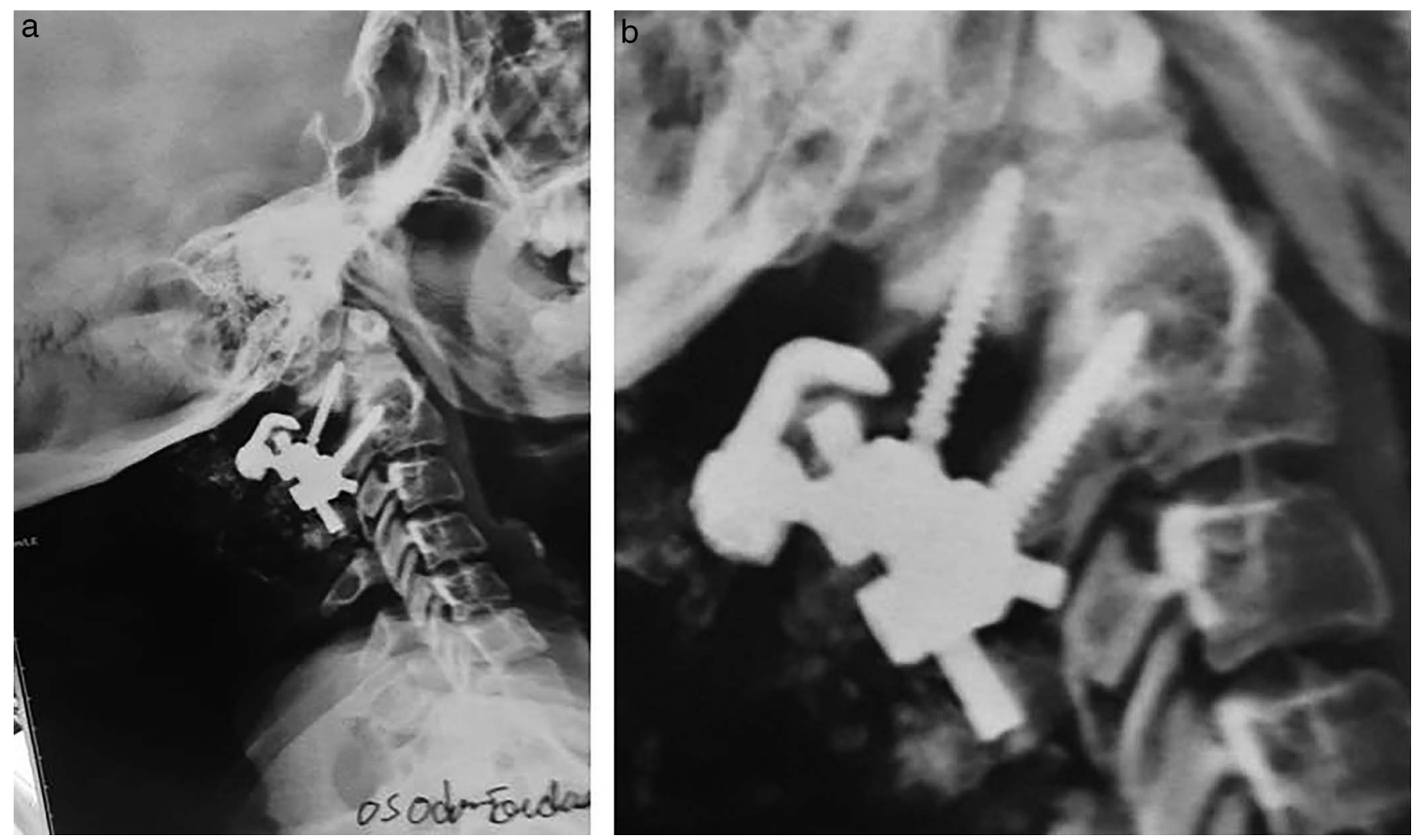

Figure 6. Early postoperative radiograph showing $\mathrm{C} 1-2$ instrumentation. 


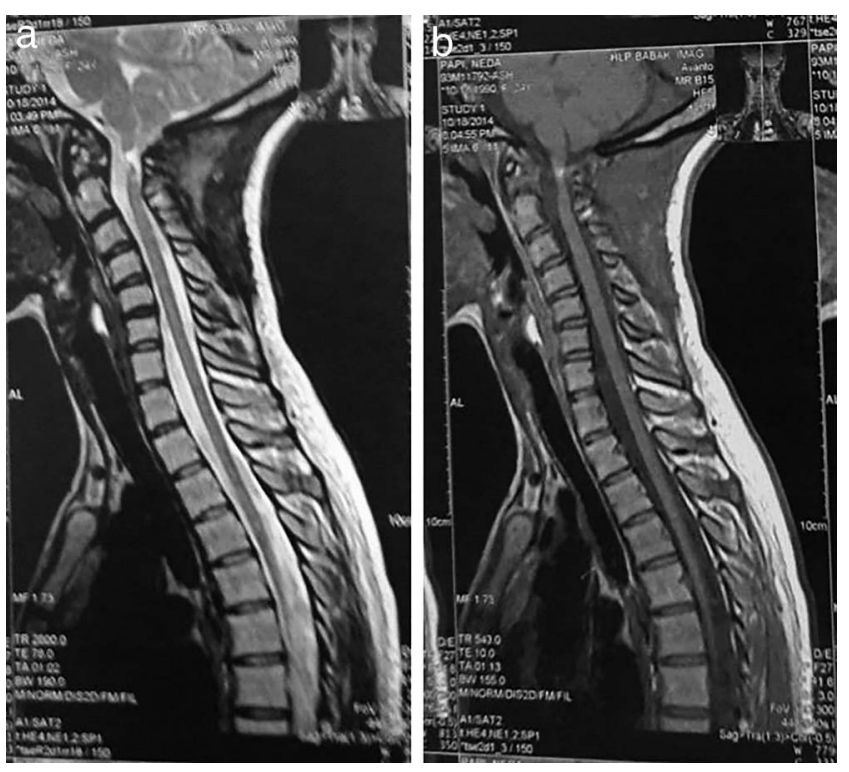

Figure 7. (a) Postoperative T1-weighted magnetic resonance image depicting appropriate decompression. (b) T2-weighted magnetic resonance imaging; besides appropriate decompression, the myelopathic patch at the craniovertebral junction is seen.

years old, the trauma from childhood was proposed to have been responsible for the later development of OO. ${ }^{19}$ This hypothesis was supported later by Joseph Stratford in 1967. In his paper he presented a 41-year-old man with progressive quadriparesis who had landed on his head after falling from a fence 25 years earlier. Radiographic evaluation of this man revealed $\mathrm{OO}$, which at that time was designated as separate odontoid. ${ }^{20}$ Trauma in childhood was likewise presumed to be the cause of later development of the patients' pathology.

The posttraumatic theory for the origin of $\mathrm{OO}$ stems largely from the work of Fielding and Griffin, ${ }^{21}$ who hypothesized that an unrecognized fracture of the dens followed by the contraction of the alar and apical ligaments leads to the upward distraction of the fragment from its normal site. The position of the fragment adjacent to the ring of the atlas is preserved by the transverse ligament. Because the blood supply at the base of the odontoid is easily traumatized, the nutrition of the distracted ossicle is then only maintained by the proximal arterial arcade. This eventually leads to the formation of an $\mathrm{OO}^{19}$; accordingly, 17 of his 35 patients with $\mathrm{OO}$ had a history of cervical spine trauma of sufficient intensity. This could have been documented if the cervical radiographs taken early following the initial injury had been normal. ${ }^{1}$

Subsequent to Fielding's theory, further support for a posttraumatic etiology was provided by a

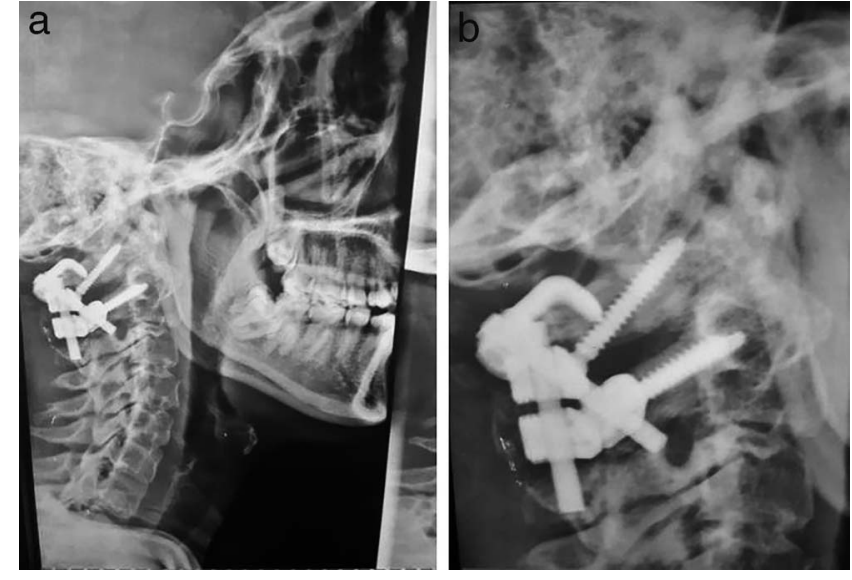

Figure 8. At 18 months' follow-up, lateral cervical radiograph shows appropriate alignment and good bony fusion.

number of authors through the use of case reports proving the traumatic origin in patients with previously documented normal radiographic imagery. ${ }^{22-24}$

In 1999, Menezes, ${ }^{25}$ in an evaluation of 260 patients with $\mathrm{OO}$, found that early childhood trauma to the craniovertebral junction $(\mathrm{CVJ})$ had been recorded in 74 patients; for 30 of these patients, normal odontoid processes were documented at the initial examination before the patient reached the age of 4 years.

Sakaida et $\mathrm{al}^{26}$ in 2001 used the term avascular necrosis for this scenario, and later, in 2007, Hammerstein suggested that with a vascular event the proximal portion of odontoid would undergo absorption, but the ossiculum terminale that have its continuous blood supply would continue to grow into an OO. ${ }^{29}$ This theory was again discussed in 2009 by Wada et al. ${ }^{30}$

In addition, a few other authors have cited the location of this specific separation and the longitudinal studies documenting the eventual posttraumatic development of an $\mathrm{OO}$ in patients whose cervical spine radiographs were initially normal following an injury. One such example is a report by Schuler et $\mathrm{al}^{27}$ in 1991, which documented the development of an OO following a significant trauma. They reported the natural history of the abnormality in a 2-year-old girl who presented with neck pain after a significant fall. Cervical radiographs obtained immediately after the traumatic incident, at 1 and then at 3 months after the injury, were decidedly unremarkable. At 4 months after injury the resorption of the dens became evident, and at 13 months the typical appearance of an $\mathrm{OO}$ 
was noticeably demonstrated on plain films. ${ }^{27}$ The first acquired $\mathrm{OO}$ in which the integrity of the odontoid process was initially observed and its alteration changed to an $\mathrm{OO}$ was confirmed through a CT scan reported by Zygourakis et $\mathrm{al}^{28}$ in 2011.

The latest report in support of the acquired theorem of etiology was made by Wang and Wang ${ }^{31}$ in 2012, where the development of an acquired OO was documented with serial CT scans. Proponents of the traumatic theory comment that older patients often cannot recall the injuries sustained in their childhood, and may thus underreport their preexisting traumas.

In contrast to this belief, in a study conducted by Sankar et $\mathrm{al}^{32}$ only 8 of 16 patients with $\mathrm{OO}$ reported previous traumatic events. Only 3 of these 8 injuries occurred with an interval remote enough to even allow remodeling of the dens to an ossicle by the time of presentation. Furthermore, 6 of the 16 patients had associated congenital anomalies within the cervical spine. Lastly, 3 of the 16 had a coexisting genetic syndrome present.

In light of these known facts, acquired theory should be accepted, but an etiology other than posttraumatic should be involved in the formation of OO. This then stands to reason in favor of a congenital theory of development.

\section{Congenital Theory}

In 1953, the embryologic origin of OO was suggested by $\mathrm{McRae}^{33}$ for the first time. This, too, was reported by the papers of several other authors, including Dyde, ${ }^{34}$ Davis and Gutierrez, ${ }^{35}$ and Currarino, ${ }^{36}$ in which the congenital etiology was also proposed. Their main theoretical belief asserts that $\mathrm{OO}$ results from the incomplete fusion of the corresponding synchondrosis located between the dens and the body of axis.

This theory is further supported by the condition's discovery in individuals who have Down syndrome and skeletal dysplasia syndromes, such as Morquio disease, multiple epiphyseal dysplasia, achondroplasia, pseudoachondroplasia, Larsen syndrome, and chondrodystrophia calcificans congenital. ${ }^{37-39}$ The presence of OO in a setting of some segmental disorders of the spine, such as KlippelFeil, bipartite atlas, hypertrophy of anterior arch of atlas, aplasia of the anterior arch of the atlas, split atlas, the absence of the posterior arch of the atlas, the hypertrophy of the posterior arch of the atlas, and basilar invagination have been regarded as being in favor of congenital etiology as well. ${ }^{39}$ The last report of this kind was released in 2011 by Yang et $a 1,{ }^{40}$ who presented the combination of $\mathrm{OO}$ with unilateral cleft of the posterior arch of atlas in a 34year-old woman. In a series of 44 patients with $\mathrm{OO}$ reported by Dai et al, ${ }^{4}$ in 18 cases coexistence of $\mathrm{OO}$ with various congenital anomalies of the cervical spine, including Klippel-Feil syndrome, occipitalization of $\mathrm{C} 1$, basilar invagination, and hypertrophy of the anterior arch of the atlas, were demonstrated.

In another study performed by Fagan et al, ${ }^{41}$ the congenital theory was reinforced by finding a history of trauma in only 1 of 18 patients with OO. The authors found a narrowing of the atlantodens joint, called the "jigsaw sign," that was consistent with a failure of segmentation of the dens from the anterior arch of the atlas.

Furthermore, the familial forms of OO have been found in 3 members of 1 family, in 2 brothers, and in identical twins, which is evidence of a genetic origin, which likewise supports the congenital hypothesis. $^{42-45}$

Finally, in a cadaveric study of OO shown by Sherk and Dawoud, ${ }^{46}$ the coexistence of ligamentous and osseous changes consistent with a congenital malformation was uncovered.

The current case involving the coexistence of $\mathrm{OO}$ and congenital aqueductal stenosis may prove to be further evidence in favor of congenital theorem.

The management of symptomatic Os Odontoideum with reducible atlantoaxial instability has evolved gradually from posterior wiring in the beginning, to $\mathrm{C} 2-1$ transarticular fixation. More recently, interventions involve $\mathrm{C} 1-2$ screw rod fixation, or Harms technique. C2 screw-C1 hook clawing has also been demonstrated to act as a strong construct for atlantoaxial fixation. ${ }^{8}$

Nonetheless, all of these procedures have been shown to provide the appropriate situation for a final arthrodesis. In our patient, using an atlas hook on one side and atlas lateral mass screw on the other side rendered an ideal fixation.

Autogenous bone graft is likewise a resourceful material for strong bony fusions, but recent studies have shown that allograft augmented with bone marrow aspirate can compete with the former noted intervention for efficacy, as was observed in our particular case. ${ }^{8}$

We also believe that the postoperative use of a Halo vest or Minerva orthosis in patients with a proportionately large head circumference in com- 
parison to their slender neck sizes, such as is observed in individuals who have a hydrocephalic or accondroplastic condition, seems well justified. Although both of these tools can prevent failure and provide a much better situation for a final arthrodesis, we came to prefer Minerva orthosis to Halo vesting with regard to the thinness of the skull in our hydrocephalic case.

In summary, although the current case is the first example of the association of $\mathrm{OO}$ and $\mathrm{AH}$ due to congenital aqueductal stenosis, our purpose was not to merely recall its rarity but to emphasize the existence of some similarities between destabilized $\mathrm{OO}$ and decompensated arrested hydrocephalus that had caused the noted and debilitating delay in the diagnosis of our patient. The fact remains that any patient with $\mathrm{OO}$ might remain asymptomatic for a long period of time or throughout the majority of his or her life until an unfortunate minor trauma triggers atlantoaxial instability. This issue will more often result in cord compressions involving progressive gait disturbances and quadriparesis that are notably more prominent in lower extremities. The same is also true in arrested hydrocephalus due to aqueductal stenosis. The patients with compensated and arrested hydrocephalus despite the presence of moderate to severe ventriculomegaly with enlargement of the head were found to be neurologically normal, with appropriate levels of attentiveness and mentation. This was evidenced in our patient, who could complete an MS degree in psychologic studies. The same can be said of $\mathrm{OO}$ in that an already arrested hydrocephalus might destabilize and progress after a minor or trivial trauma. A patient with decompensated arrested hydrocephalus will then also gradually develop gait disturbances and clinically show some spastic paraparesis. For this reason, the physician of a patient should not be criticized for a delay in the diagnosis or in their approach to the appropriate treatments.

\section{REFERENCES}

1. Fielding JW, Hensinger R, Hawkins R. Os odontoideum. J Bone Joint Surg Am. 1980;62(3):376-383.

2. Ducker T. Os odontoideum. J Spinal Disord. 1993;6(4):364-365.

3. Menezes AH. Pathogenesis, dynamics, and management of os odontoideum. Neurosurg Focus. 1999;6(6):e4.

4. Dai L, Yuan W, Ni B, Jia L. Os odontoideum: etiology, diagnosis, and management. Surg Neurol. 2000;53(2):106-109.

5. Klimo P Jr, Kan P, Rao G, Apfelbaum R, Brockmeyer D. Os odontoideum: presentation, diagnosis, and treatment in a series of 78 patients: clinical article. J Neurosurg Spine. 2008;9(4):332-342.

6. Arvin B, Fournier-Gosselin MP, Fehlings MG. Os odontoideum: etiology and surgical management. Neurosurgery. 2010;66(3 Suppl):22-31.

7. Spierings E, Braakman R. The management of os odontoideum: analysis of 37 cases. J Bone Joint Surg Br. 1982;64(4):422-428.

8. Rahimizadeh A, Rahimizadeh A. Os odontoideum: a review article. Orthop Res Traumatol. 2016;1(2):33-55.

9. Kirkpatrick M, Engleman H, Minns RA. Symptoms and signs of progressive hydrocephalus. Arch Dis Child. 1989;64(1):124-128.

10. James HE, Schut L. Pitfalls in the diagnosis of arrested hydrocephalus. Acta Neurochirugica. 1978;43(1-2):13-17.

11. Larsson A, Stephensen H, Wikkelson C. Adult patients with asymptomatic and compensated hydrocephalus benefit from surgery? Acta Neurol Scand. 1999;99(2):81-90.

12. McLone DG, Aronyk KE. An approach to management of arrested and compensated hydrocephalus. Pediatr Neurosurg. 1993;19(2):101-103.

13. Dickerman RD, McConathy WJ, Lustrin E, Schneider SJ. Rapid neurological deterioration associated with minor head trauma in chronic hydrocephalus. Childs Nerv Syst. 2003;19(4):249-251.

14. Garber JN. Abnormalities of the atlas and axis vertebrae - congenital and traumatic. J Bone Joint Surg Am. 1964;46:1782-1791.

15. Hawkins R, Fielding J, Thompson W. Os odontoideum: congenital or acquired: a case report. J Bone Joint Surg Am. 1976;58(3):413-414.

16. Brannon EW. Congenital malformation of the atlantoaxial joint with dislocation. $J$ Bone Joint Surg Am. 1960;42:1377-1380.

17. Gillman E. Congenital absence of the odontoid process of the axis. J Bone Joint Surg Am. 1959;41A:345-A348.

18. Schiller F, Nieda I. Malformation of the odontoid process - report of a case and clinical survey. Calif Med. 1957;86(6):394-398.

19. Bachs A, Barraquer-Bordas L, Barraquer-ferrf L, Canadell J, Modolell A. Delayed myelopathy following atlanto-axial dislocation by separated odontoid process. Brain. 1955;78(4):537-553.

20. Stratford J. Myelopathy caused by atlanto-axial dislocation. J Neurosurg. 1957;14(1):97-104.

21. Fielding JW, Griffin PP. Os odontoideum: an acquired lesion. J Bone Joint Surg Am. 1974;56(1):187-190.

22. Riccardi JE, Kaufer H, Louis DS. Acquired os odontoideum following acute ligament injury: report of a case. J Bone Joint Surg Am. 1976;58(3):410-412.

23. Stillwell WT, Fiedling JW. Acquired os odontoideum: a case report. Clin Orthopaed Relat Res. 1978;135:71-73.

24. Clements W, Mezue W, Mathew B. Os odontoideumcongenital or acquired? - that's not the question. Injury. 1995;26(9):640-642.

25. Menezes AH. Pathogenesis dynamics and management of os odontoideum. Neurosurg Focus. 1999;6(6):2e.

26. Sakaida U, Waga S, Kojima T, Kuba Y, Niwa S, Matsubara T. Os odontoideum associated with hypertrophic ossiculum terminalis: case report. J Neurosurg. 2001;94(1 Suppl):140-144. 
27. Schuler TC, Kurz L, Thompson DE, Zemenick G, Hensinger RN, Herkowiz HN. Natural history of os odontoideum. J Pediatr Orthop. 1991;11(2):222-225.

28. Zygourakis CC, Cahill KS, Proctor MR, Corinna C. Delayed development of os odontoideum after traumatic cervical injury: support for a vascular etiology: case report. $J$ Neurosurg Pediatrics. 2011;7(2):201-204.

29. Heick A. Juvenile avascular necrosis of the odontoid process: a review on the etiology of os odontoideum and absentia odontoidei. Dan Med Bull 1996;43(4):363-366.

30. Wada E, Matsuoka T, Kawai H. Os odontoideum as a consequence of a posttraumatic displaced ossiculum terminale. A case report. J Bone Joint Surg. 2009;91(7):1750-1754.

31. Wang S, Wang C. Acquired os odontoideum: a case report and literature review. Childs Nerv Syst. 2012;28:315-319.

32. Sankar WN, Wills BP, Dormans JP, Drummond DS. Os odontoideum revisited: the case for a multifactorial etiology. Spine (Phila Pa 1976). 2006;31(9):979-984.

33. McRae D. Bony abnormalities in the region of the foramen magnum: correlation of the anatomic and neurologic findings. Acta Radiol. 1953;40(2-3):335-354.

34. Dyde JDyde J. Chronic atlanto-axial dislocation due to a separateodontoid process. Guys Hosp Rep. 1963;112:113.

35. Davis D, Gutierrez F. Congenital anomaly of the odontoid in children. Pediatr Neurosurg. 1977;3(4):219-229.

36. Currarion G. Segmentation defect in the midodontoid process and its possible relationship to the congenital type of os odontoideum. Pediatr Radiol. 2002;32(1):32-34.

37. Taggard DA, Menezes AH, Ryken TC. Instability of the craniovertebral junction and treatment outcomes in patients with Down's syndrome. Neurosurg Focus. 1999;6(6):E5.

38. Rahimizadeh A, Soufiani HF, Hassani V, Rahimizadeh A. Atlantoaxial subluxation due to an os odontoideum in an achondroplastic adult: report of a case and review of the literature. Case Rep Orthop. 2015;2015:142586.

39. Ogata $T$, Morino $T$, Hino M, Miura H. Cervical myelopathy caused by atlantoaxial instability in a patient with an os odontoideum and total aplasia of posterior arch of the atlas: case report. J Med Case Rep. 2012;6:1-5.

40. Yang J, Ni B, Yan W, Zhou F, Chen J. Post atlantoaxial fusion for unilateral cleft of atlas posterior arch associated with os odontoideum: case report and technique note. Eur Spine J. 2011;20(2):284-288.

41. Fagan AB, Askin GN, Earwaker JW. The jigsaw sign: a reliable indicator of congenital aetiology in os odontoideum. Eur Spine J. 2004;13(4):295-300.

42. Morgan MK, Onofrio BM, Bender CE. Familial os odontoideum: case report. J Neurosurg. 1989;70(4):636-639.

43. Wang S, Wang C. Familial dystopic os odontoideum. JBJS Case Connect. 2011;(9):e44.

44. Kirlew KA, Hathout GM, Reiter SD, Gold RH. Os odontoideum in identical twins: perspectives on etiology. Skeletal Radiol. 1993;22(7):525-527.

45. Verska JM, Anderson PA. Os odontoideum: a case report of one identical twin. Spine (Phila Pa 1976). 1997;22:706-709.

46. Sherk HH, Dawoud S. Congenital os odontoideum with Kleppel-Feil anomaly and fatal atlanto-axial instability. Report of a case. Spine (Phila Pa 1976). 1981;6(1):42-45.

Disclosures and COI: The authors received no funding for this study and report no conflicts of interest.

Corresponding Author: Abolfazl Rahimizadeh, MD, Department of Spinal Surgery, Pars Advanced and Minimally Invasive Manners Center (PAMIM), Pars Hospital, Keshawrz Blvd, Tehran, Iran. Phone: +98 91232261 49; Email: a-rahimizadeh@hotmail.com.

Published 15 October 2018

This manuscript is generously published free of charge by ISASS, the International Society for the Advancement of Spine Surgery. Copyright @ 2018 ISASS. To see more or order reprints or permissions, see http://ijssurgery.com. 